\title{
Editorial: The local, national and global communities: Identifying with one or all
}

Consider the following list: Bhutan, Brunei Darussalam, Burkina Faso, Cape Verde, Comoros, Guinea-Bissau, Kiribati, Kyrgyzstan, Marshall Islands, Nauru, Palau, São Tomé, Tajikistan, Turkmenistan, Uzbekistan and Vanuatu. What do they all have in common? I think even the most sophisticated readers could be forgiven if they did not immediately come up with the answer. The fact is that each of these sovereign states is a fully fledged member of the United Nations. ${ }^{1}$

Since the end of the Cold War and the fall of the Berlin Wall, the main geopolitical trend on the planet has been for the acceleration of one of the principal purposes of the United $\mathrm{Na}$ tions; that is self-determination. There are now 188 full-member states in the United Nations, and that still excludes Switzerland, which remains an observer.

At the same time, the principal economic trend on the planet has been Globalisation and largely for the same reason. As the market system has largely won there are new markets for the world's multi-national corporations to conquer and new media, which pay scant attention to the political boundaries, to help them in the process. Fifty of the world's largest economies are, in fact, corporations.

Here in Europe it is sometimes difficult to recognise these trends, as our own politicians seem to want to take us in the opposite direction. They are working to draw the member nations of the European union into an ever closer, ever more integrated body. At the same time they resist the pressures of Globalisation as far as they are able. This of course means that there are very few European companies that can describe themselves as global in the way that the giant American and Asian corporations can.

In Europe there are 15 member nations of the European Union but there are 45 official languages spoken by their peoples, and that is not including the dialects of their indigenous populations such as Geordie nor the tongues of their more recent immigrants such as Gujerati. In the UK this dichotomy has led to the process of devolution, ostensibly a return of power to local and regional assemblies.

Remember the extraordinary scenes at the WTO round in Seattle? ${ }^{2}$ On the 30th November, 1999 the mayor of Seattle was forced to declare a state of emergency as a result of violent Anti-WTO street protests. The mission of the WTO is to create a prospering global economy, increasing the flow of goods and services around the world. But critics argue that most of the planet's population will not benefit from WTO actions and may, in fact, be harmed by them. This is a subject of 
huge importance but, whatever the merits of either argument, this is the political and economic background against which brand owners have to manage their assets.

\section{THE NEW AND EVOLVING CHALLENGES TO THE WORLD'S GREAT BRAND OWNERS}

There is a new factor at play, and that is the Internet. While much of the impact of the Internet has been exaggerated, it is certainly going to change the way we work in a fundamental way. It is possible that the role of the middleman will change forever or even disappear. The supply chain will be streamlined; inventory collapsed and much quicker response to real market demand will be possible. These are factors that encourage Globalisation.

We are told that it will be possible to hold one-to-one relations with the consumer. ${ }^{3}$ Here I am more sceptical. While I acknowledge that interactive communication between a manufacturer and his consumer is theoretically possible, the reason why these big companies developed in the first place was that they could achieve economies of scale that the local producer could not match. Once these are sacrificed the advantage of the large producer is lost. This tension is particularly interesting in the retail arena. I used to believe that there were no global retailers. Often national champions from the USA would come over to Europe and fall flat on their fascia. Some brave Brits tried the reverse but with the same result. Then those retailers who controlled most of their product supply chain in a vertical model had some success. These included petrol retailers, Esso and Shell, restaurant chains, McDonalds and Pizza Hut and a few clothing retailers Marks \& Spencer and The Gap. They were not selling other brands except as accessories to the central purchase. But now the giants who have to expand beyond their home markets are flexing their muscles. Is this just a continuation of the same inevitable consolidation that started when an owner manager opened his second store? Or are their fundamental barriers that frustrate this process at the local, regional, national or international level?

One important barrier is people. When an owner-manager opens his second store he needs to trust the person who looks after it. That is why this is so often a family member. But the size of the family will be a constraint to growth. If he solves this his next barrier will be geography. He will want to visit each of his stores every day, checking on his staff, motivating them and transferring success around his stores. When this is physically impossible he will need a second tier of management. If he solves that he can grow quickly if his finances permit. In the UK and the USA public funding or equity has usually assisted progress through this barrier. In Germany it has been more normally by bank finance or debt. The German system of banking has also provided a degree of protection to the local operator.

If we contrast the models of a retailer developing his organisation through the barriers of management, geography and finance with a manufacturer it is clear that the manufacturer has an advantage. First, the manufacturer can access the benefits of economy of scale without complexity in his organisation. Second, he can distribute through available channels 
wherever they may be without equivalent investment. Thus he can invest the proceeds of economy of scale in widening the brand franchise. When in his history he chooses to take his brand overseas, he can do this initially in a low risk way by export and then, when he has built up economy of scale in the new market, he can begin to invest in local production either by acquisition or by start-up. He will certainly have a brush with local politicians at this stage. His locally based competitors will accuse him of dumping and eventually he will choose to invest in local production, partly to avoid these tedious accusations and partly to be seen as a good corporate citizen. Of course

he will exact a price for his beneficence in terms of tax holidays or grants.

\section{CHARACTERISING THE WORLD MARKETS: UK, USA, EUROPE AND JAPAN}

\section{Lessons to be learned}

To what extent does this vary by the major regions of the world? I have worked for American, Japanese and British brand owners and I can assuredly say that there are marked variations between them. But there are variations among different companies from the same region. I can tell you what it is like to work for Sony but I am not sure that I can tell you what it is like to work for the Japanese.

The regional variations are certainly as marked. The USA is pivotal to many markets. It is a vast market though within it there are massive variations. There are no truly national newspapers but a single spot on the Superbowl can announce a new product to over 100 million people. Most of the brands that figure in any list of global brands are American. This is the result of their inventiveness; the strength of their home market; their success in brand development. It may also be the result of the pervasiveness of their culture and the fact that a business career is seen as attractive and therefore attracts the best graduates from their schools.

Any non-US-based corporation must succeed in the USA if its ambition is global. The extraordinary success of Sony as a truly global brand is probably based on the fact that Akio Morita recognised this truth early in the company's history. He established his family home in New York and personally supervised the business. The products were exported from Japan to America but the reputation of the company was exported from America to the rest of the world.

A distinguished professor from Harvard told me recently that there is nothing happening in Europe. Perhaps this is harsh and not true in some specific industries, such as motor cars and fashion, where the European gift for design stimulates innovation. But certainly the USA and Japan lead the new industries of information and technology. An exception has been cellular telephones where an unusual combination of deregulation, led by the UK, and agreement on a standard has created a vibrant market led by worldclass producers, Nokia and Ericsson, and service providers such as Vodafone and Orange.

But the reality is that there are few global brands and practically no global corporations. To examine the truth of this let us consider some of the leaders whenever there is any consideration of this question. 


\section{SUCCESS CRITERIA FOR MANAGING GLOBAL BRANDS}

'Unilever is dedicated to meeting the everyday needs of people everywhere', according to their website. 'Around the world people use its products 150 million times a day.' There is no question, that in most people's minds, Unilever would figure as a global company. But consider what they go on to say: 'Unilever has identified five food categories of key importance: culinary, frozen foods, ice cream, tea and yellow fats. Each of these will benefit from the guidance of its core category team, through enhanced strategy, improved management of brand equity, and the careful promotion of innovation and excellence.'

Foods Category director Lex Kemner explains:

'In terms of world markets, these categories represent businesses of enormous size and importance where we have excellent competence. This is especially true in ice cream, tea-based beverages and yellow fats, in which Unilever holds high market shares around the world.

The opportunity for leveraging lies in the fact that market share is so inevenly distributed (my italics), with more than 75 per cent of the foods business concentrated in Europe and North America. In some regions only two categories are represented and there is a striking mismatch between Unilever's food sales and the growth markets of the developing and emerging countries. (Again, my italics.) Inevitably different categories require different categories require different approaches: ice cream and tea have a global quality and can "travel" easily, but tastes in yellow fats vary enormously from one region to another and culinary is also very much driven by regional needs.'
Or consider another European food giant, Danone. ${ }^{5}$ Again, a visit to their web-site reveals that they regard themselves 'as a global corporation', but 'DANONE approaches the world with respect for diversity of cultures deeply rooted in solid, fundamental values. Around the globe, Danone represents healthy eating, well-being, quality and good times shared with family and friends. Danone's dynamic incorporates a people-oriented consideration of the culinary preferences and habits that define cultures right down to the details of their everyday life.' So far, so good, but later on we find: 'The Danone Group's leading brands are Danone, LU and Evian, which represent nearly 40 per cent of our sales. They share a strong worldwide presence, well illustrated by the Danone brand: originally a dairy-food brand, it now represents babyfood in Russia and China, a natural spring water in the United States, and cookies in Asia and Brazil' (my italics). No doubt all of this adds up to a very successful business with wide international reach, but is it global?

The Americans express it better. Look at Colgate. ${ }^{6}$ 'Colgate', we are told, 'serves global consumers with products in five major categories oral care, personal care, household surface care, fabric care, and pet nutrition.' On fabric care, 'Washing clothes is a universal part of life around the world. But the methods vary widely from area to area. That's why Colgate produces a multitude of detergents in many forms. They include laundry bars for hand washing in rivers or tubs, and powders and liquids for automatic machines. In many countries, "Fab" is the word consumers use when they ask for detergents.' 
'In addition to detergents, Colgate also markets fabric softeners on six continents. In many countries, Colgate has created the category with the "Soupline", "Suavitel" and "Softlan" brands and is the worldwide leader 'outside the USA where we compete.' To my mind a much more convincing case for globalisation and the key is the management structure.

Consider how the Daddy of them all, Procter \& Gamble approached this. $P \& G$ has been an international marketer for more than half a century. But until the mid 1970s, P\&G did not really think on a global basis. Most of their international business consisted of US brands transplanted to other countries, or local brands created by $\mathrm{P} \& \mathrm{G}$ subsidiaries. ${ }^{7}$

The company began to think about leveraging brands and technology on a transnational basis in the European marketplace in the late 1970s. This was a significant shift in thinking that was a precursor to true Globalisation about ten years later. To create global brands required a change in the way the company was managed across borders. The mini-fiefdoms of the country managers that replicated the US structure, but duplicated resource and led to slow rollout of new products had to be dismantled. Instead cross-functional and cross-regional teams were formed. This became the pattern for the world. Developing the business on a global basis is now a strategic objective of the company. Japan is the largest consumer market outside the USA and arguably the toughest, most competitive, fastestmoving consumer market in the world. Ed Artzt, the CEO of P\&G at that time said, 'Compete with them in their own backyard, for you will eventually have to compete with them at home to be anything but successful there.' And they were.

The key was a rigorous adoption of the much-quoted maxim: Think Global, Act Local. In the case of P\&G this is facilitated by the strong culture that has been successfully exported around the world.

In the words of John Smale, another CEO, 'Procter \& Gamble people all over the world share a common bond. In spite of cultural differences, we speak the same language. When I meet with Procter \& Gamble people whether they are in sales in Boston, Product development at the Ivorydale Technical Centre, or the management committee in Rome - I feel I am talking to the same kind of people. People I know. People I trust. Procter \& Gamble people.' P\&G now has about a thousand expatriates from different countries working in locations outside their countries. These managers help to internationalise and homogenise the $P \& G$ culture around the world as they move from country to country.

But recent downgrading of $P \& G$ 's profits and market capitalisation suggest that even these efforts are not a panacea.

In Sony there is similar emphasis on international experience. The new markets were invariably opened up by young bright aggressive Japanese with the pioneer spirit and the ability to inculcate the culture in the nationals that they hire to succeed them when they returned. My first Japanese boss spent over 20 years of his life outside Japan. He spent a full day with me shortly after I joined explaining the culture. How many bosses give that much of their time?

In a recent Marketing Society Mas- 
terclass, Professor John Quelch, Dean of London Business School, coined Isaac Newton's Law of Global Marketing, ie 'to every global action there is an equal and opposite reaction'. ${ }^{8} \mathrm{He}$ was particularly thinking of Coca-Cola who perhaps took the cause of Globalisation further than any other corporation but after some unfortunate experiences in 1999, has given a mandate to its new Chairman and Chief Executive, Douglas Daft to localise the company. He now says, 'think local, act local ... In every community, we must remember we do not do business in markets, we do business in societies.'

I have recently joined NXT plc as CEO. Our vision is to establish a new global standard for loudspeakers by licensing our flat panel loudspeaker technology. Originally a British HiFi manufacturer, our scientists made a breakthrough invention and it was clear that we had to transform ourselves into a global operation. As a small company with global reach we can learn the lessons that I have espoused and seek worldwide brand recognition from the start.

\section{SUMMARY OF THE KEY SUCCESS CRITERIA FOR MANAGING GLOBAL BRANDS}

- 1 Brands are brands are brands.

By which I mean that the rules of brand management are fundamental and apply equally whether a brand is local or international. There are then some additional rules that apply to international brands.

-2 Respect the evolution of brands.
One of these is that if a brand has enjoyed a glorious history in Country A then to achieve similar glory in Country B it will have to go through the same stages of development. It is possible that this process can be quickened because of the reflected glory from Country A or because of the confidence of a success story, but the consumer still needs to see the film of the book in the right order.

- 3 People make the difference.

True as in everything, but you will need people to develop international experience to manage global brands and you will probably have to create them.

- 4 Accountability.

Do not complicate the structure.

\section{David Pearson Editorial Board}

\section{References}

(1) United Nations Website.

(2) http://Cnn.com/Us/9911/30/wto.03/

(3) Peppers, Don and Rogers, Martha (1996) 'The one-to-one future: building business relationships one customer at a time', Judy Piatkus (Publishers) Ltd.

(4) Unilever Website: www.unilever.com/Unilever's Foods Business.

(5) Danone Website: www.danonegroup.com/Meet The Danone Group/Danone Worldwide/.

(6) Colgate Website; www.colgate.com/Our Global brands.

(7) Decker, C. (1998) P\&G 99-99 'Principles and Practices of Procter \& Gamble's success', Harper Collins Business.

(8) Marketing Society Masterclass, Professor John Quelch, 16th February, 2000.

(9) Daft, Douglas (2000) 'Back to Classic Coke', Financial Times, 27th March. 